\title{
Overnutrition and Scholastic Achievement: Is There a Relationship? An 8-Year Follow-Up Study
}

\author{
Ofelia C. Flores $^{a}$ Yasna Z. Orellana ${ }^{a}$ Bárbara D. Leyton ${ }^{a}$ \\ Rodrigo B. Valenzuela ${ }^{b}$ Cynthia R. Barrera ${ }^{b} \quad$ Atilio F. Almagià ${ }^{c}$ \\ Víctor C. Martínez ${ }^{d}$ Daniza Ivanovic ${ }^{a}$ \\ ${ }^{a}$ Dr. Fernando Monckeberg Barros, Institute of Nutrition and Food Technology (INTA), \\ University of Chile, Santiago, Chile; ${ }^{b}$ Department of Nutrition, Faculty of Medicine, \\ University of Chile, Santiago, Chile; ' Institute of Biology, Laboratory of Physical \\ Anthropology and Human Anatomy, Faculty of Sciences, Pontificia Universidad Católica \\ de Valparaíso, Valparaíso, Chile; ${ }^{\mathrm{d} D e p a r t m e n t ~ o f ~ C o m m e r c i a l ~ E n g i n e e r i n g, ~ F a c u l t y ~ o f ~}$ \\ Economics and Business, University of Chile, Santiago, Chile
}

\section{Keywords}

Overweight - Obesity - Scholastic achievement - Education - BMI - Socio-economic status . Family relations Students

\begin{abstract}
Objective: The aim of this study was to assess the association between overnutrition and scholastic achievement (SA). Methods: A representative and proportional sample of 477 children of the 5th elementary school grade of both genders was randomly chosen during 2010, in the Metropolitan Region of Chile. SA was measured through the 2009 Education Quality Measurement System (SIMCE) tests of language (LSA), mathematics (MSA) and understanding of the natural environment (UNESA). Current nutritional status was assessed through the body mass index Z-score (Z-BMI). Nutritional quality of diet, schedule exercise, socioeconomic status, family, and educational variables were also recorded. Four and 8 years later, SA was assessed through the 2013 SIMCE and the University Selection Test (2017 PSU), respectively. Results: Socioeconomic status, the number of repeated school years, and maternal schooling were strong predictors of 2009 SIMCE and the independent variables with the greatest explanatory power for LSA (Model $R^{2}=0.178 ; p<0.00001$ ) variances, besides of gender for MSA (Model $R^{2}$ $=0.205 ; p<0.00001$ ) and UNESA (Model $\left.R^{2}=0.272 ; p<0.00001\right)$. Overnourished children did not have significantly lower 2009 and 2013 SIMCE and 2017 PSU outcomes. Conclusions: These results confirm that overnourished children did not achieve significantly lower SA.
\end{abstract}

(C) 2018 The Author(s)

Published by S. Karger $\mathrm{GmbH}$, Freiburg

Prof. Daniza Ivanovic

Dr. Fernando Monckeberg Barros, Institute of Nutrition and Food Technology (INTA) University of Chile

Avda. El Líbano 5524, Santiago, Chile

daniza@inta.uchile.cl 
Flores et al.: Overnutrition and Scholastic Achievement: Is There a Relationship? An 8-Year Follow-Up Study

\section{Introduction}

In Chile, overweight and obesity in schoolchildren and in the population over the age of 15 years has increased in recent decades, despite efforts at prevention [1-3]. As a result of the high prevalence of childhood overnutrition, there is an increase in the incidence of diseases such as type 2 diabetes, cardiovascular disease, hypertension, hyperlipidemia, obstructive sleep apnea, asthma, orthopedic complications, and psychosocial problems which reduce the quality of life beginning at an earlier age $[4,5]$.

Most of the research has focused on studying the effects of overnutrition on health, and fewer studies have examined its associations with scholastic achievement (SA). The causes of the relationship between overnutrition and SA are uncertain; however, several psychosocial (self-esteem, depression), family (parental interaction with the child, number of hours per day that children watch television), nutritional and educational factors (amount of hours of physical education, school characteristics) have been shown to correlate with educational aspects and BMI [6-13]. Considering that students spend most of their awake time in educational institutions, it is possible that the effects of overnutrition will affect their SA, learning skills, and attendance [14].

Socioeconomic status and parental schooling have also been proposed as variables that contribute to explain the relationship between overnutrition and SA, since these social factors may independently affect this relation [15]. The aim of this study was i) to determine the association between overnutrition and SA in school age children of the 5th elementary school grade in the Metropolitan Region of Chile at the onset of the school year in 2010 using the Education Quality Measurement System (SIMCE) tests of language (LSA), mathematics (MSA) and understanding of the natural environment (UNESA), at the end of 2009 when they graduated from the 4 th grade of elementary school; ii) to analyze the association between overnutrition and SA 4 and 8 years later, when they graduated from elementary (8th grade of elementary school) and high school (4th grade of high school) using the 2013 SIMCE and the 2017 University Selection Test (PSU), for university admission, respectively. The purpose was to confirm the hypothesis that overnourished school age children achieve significantly lower SA compared with their normal-weight peers.

\section{Subjects and Methods}

\section{Study Design}

This is a cross-sectional, correlational and follow-up study.

\section{Population}

The target population ( $\mathrm{N}=91,663 ; 39 \%$ of Chilean school population) included all 5 th grade elementary school age children in the Metropolitan Region of Chile in 2010, who took the SIMCE tests at the end of November 2009 and 2013, when they were graduating from the 4th and 8th grades of elementary school, respectively, and the 2017 PSU at the end of November of this year, when they graduated from high school, for university admission. As regards to type of school, they were enrolled in public, private subsidized and private non-subsidized schools from urban areas.

Sample

The sampling frame of this study corresponds to the educational establishments from the urban area of the Metropolitan Region of Chile. The sampling was performed as follows: firstly, 33 educational establishments, which represented $2.61 \%$ of the total population of urban schools $(N=1,262)$ were randomly selected by proportional allocation according to stratification by type of school, level of SA of the educational establishments in the 2009 SIMCE tests established by the Ministry of Education (high, medium, and low), and gender. Secondly, all students enrolled in the 5th elementary school grade during March 2010 and who took 
Flores et al.: Overnutrition and Scholastic Achievement: Is There a Relationship? An 8-Year Follow-Up Study

the 2009 SIMCE tests in each one of the 33 schools were invited to participate in the study. A total of 682 school age children (males $n=379$ ) ( $95 \%$ of the original sample) as well as their parents agreed to participate and signed the informed consent form. In the present study, 477 school age children (mean age $10.7 \pm 0.5$ years; range 9.9-14.4 years, with 263 (55.1\%) males) and their parents were considered since they attended all evaluations. 2009 SIMCE outcomes in the LSA, MSA and UNESA tests were requested from the Ministry of Education in January 2010, when we received the approval of Grant FONDECYT 1100431. At the onset of March 2010, the Ministry of Education gave us the results of the 2009 SIMCE tests for each of the school age children according to type of school, level of SA of the educational establishments in the 2009 SIMCE tests and gender, and then the sample was selected.

This study was approved by the Committee of Ethics in Studies on Humans of the Dr. Fernando Monckeberg Barros, Institute of Nutrition and Food Technology (INTA), University of Chile and ratified by the Committee of Bioethics of the National Fund for Scientific and Technologic Development (FONDECYT), Chile. The subjects' consent was obtained according to the norms for Human Experimentation, Code of Ethics of the World Medical Association (Declaration of Helsinki) [16].

Data Collection Conducted during 2010.

Between March to May 2010 the following data were collected:

\section{SIMCE Tests}

SA was assessed through the 2009 SIMCE tests, which has national coverage and is administered by the Agency for Education Quality from the Ministry of Education; this was considered the dependent variable. As we said previously, school age children took the SIMCE tests in November 2009, that is at the end of the school year, when they were graduating from the 4th grade of elementary school at the end of the first cycle of elementary school. As we mentioned before, at the onset of March 2010, the Ministry of Education gave us the results of the 2009 SIMCE tests. The aim of this testing is to improve the quality and equity of the educational process in the different areas covered by the national curriculum. Scores range between 0 and 400 , and the results were expressed as scores (mean \pm SD) in LSA, MSA and UNESA tests. [17].

Current Nutritional Status

Anthropometric measurements were performed through standardized procedures [18]. Weight (W) was measured in a platform beam balance SECA model L 700 with an accuracy of 50 g. Height $(\mathrm{H})$ was determined with a vertical rod with a measuring scale of up to $2 \mathrm{~m}$ of height, with an accuracy of $0.5 \mathrm{~cm}$. When measuring height, the subject stands straight looking ahead with Frankfurt plane horizontal, with shoulders blades, buttocks, and heels almost together touching measurement board, arms at sides, legs straight, knees together and feet flat [18]. The current nutritional status was assessed through the BMI (evaluated as $\mathrm{W} / \mathrm{H}^{2}$ ) which was calculated using biological age derived from Tanner stages and expressed as BMI Z-score (2010 Z-BMI) [19]. 2010 Z-BMI was compared with NCHS-CDC tables, and children were distributed into three categories: normal $(\mathrm{N})$, Z-BMI score between -1 and +1 ; overweight (OW), Z-BMI score between $>+1$ and +2 as well as obesity (OB), Z-BMI score $>+2[20,21]$. This was considered the independent variable.

\section{Control Variables}

Nutritional Quality of Diet

Nutritional quality of diet was determined by means of a self-administered questionnaire previously validated for children and adolescents in Chile [22]. The instrument evaluated five categories: 1 . The number of daily meals and the quality of food served at 2. Breakfast, 3. Lunch, 4. Dinner and, 5. Snack at home and at school. A total of 110 foods and beverages were assessed. For each meal, the frequency of consumption of the food was expressed as daily, 3-5 times a week, 1 or 2 times a week, or never. In each meal, the foods were grouped and scored as follows: i) Foods high in fat and sugars were scored with 0; ii) normo-fat foods with score 1 and, iii) foods rich in fiber and low in saturated fat or sugar with score 2. Each of the five categories was evaluated with a score ranging from 0 to 2 , so the total score of the questionnaire ranged between 0 and 10. Higher scores are related with better nutritional quality of diet. The cut-offs for the Chilean children were used for classifying the nutritional quality of diet of the sample into three groups: unhealthy $(\leq \mathrm{p} 25$, score $\leq 4.3$ ), fair ( $>$ p 25 and $<$ p 75, score 4.4-5.9) and healthy ( $\geq p$ 75, score $\geq 6.0$ ) [22]. 
Flores et al.: Overnutrition and Scholastic Achievement: Is There a Relationship? An 8-Year Follow-Up Study

Scheduled Exercise

Scheduled exercise was measured through a self-administered questionnaire previously validated using activity monitors based on accelerometry $[22,23]$. The questionnaire considers five categories: 1 . daily hours lying down, 2. daily hours of sitting activities, 3. number of blocks walked daily, 4. daily hours of outdoor recreational games and, 5. weekly hours of exercises or scheduled sports. The activities of the weekend are not considered to be very irregular, except sports activities. Each category has a score between 0 and 2, by which the total score ranged from 0 to 10 with 0 indicating null physical activity and 10 representing the compliance with the standards of the World Health Organization (WHO): children and young people from 5 to 17 years of age should perform at least $60 \mathrm{~min} /$ day in moderate to vigorous physical activities [24]. The cut-offs for the Chilean children were used to classify children into three groups: physically inactive $(\leq \mathrm{p} 25$, score $\leq 3)$, moderately active $(>\mathrm{p} 25$ and $<\mathrm{p} 75$, score 3.1-5.9), and physically active $(\geq \mathrm{p} 75$, score $\geq 6)[22,23]$.

Socioeconomic, Sociocultural, Family, and Educational Variables

School age children and their parents were separately interviewed at school in order to know their socioeconomic status and some sociocultural, family and educational conditions. Socioeconomic status was measured using Graffar's modified scale which includes schooling and occupation of the household head and characteristics of the housing (building materials, ownership, water supply, and ownership of durable goods), which has been validated for Chilean urban and rural populations [25]. This scale classified the sample into five socioeconomic strata: 1 = high; 2 = medium-high; 3 = average; 4 = medium-low; 5 = low and 6 = extreme poverty. In the present study children were grouped as follows: high $(1+2)$, medium (3), and low $(4+5+6)$.

Family recreation activities, the family support for studies at home, and paternal and maternal schooling were also registered. Family recreation activities were considered as an ordinal qualitative variable: 'Do you participate in recreational activities with your family?' 1 = always, 2 = frequently, $3=$ sometimes, $4=$ never. Family support for studies at home was also considered as an ordinal qualitative variable: 'At home, does your family help you in your studies?' 1 = always, 2 = sometimes, 3 = never. Paternal and maternal schooling were discrete quantitative variables expressed as completed years of study.

Type of school was considered as a nominal qualitative variable and categorized as follows: $1=$ public, 2 = private subsidized, 3 = private non-subsidized. The number of repeated school years, a discrete quantitative variable, was classified from 0 (no year repeated) to a maximum of 3 years. Student relationships with their teachers and classmates were considered as ordinal qualitative variables, grouped according to the following categories: 1 = very adequate, 2 = adequate, 3 = fair, 4 = inadequate, 5 = very inadequate.

Follow-Up Study

Four years later, when school-age children graduated from elementary school (8th grade of elementary school), they took the 2013 SIMCE tests in November 2013 which have national coverage and administered by the Agency for Education Quality from the Ministry of Education. Results were expressed as scores (mean \pm SD) in LSA, MSA and UNESA tests [17].

Eight years later, at the end of November 2017, school age children graduated from high school (4th grade), and they took the 2017 PSU. LSA and MSA scores in the 2017 PSU were provided by the Department of Evaluation, Measurement and Educational Registry (DEMRE) of the University of Chile and by the Studies Center of the Ministry of Education at the onset of June 2018 as part of the development of Grant FONDECYT 1150524. The PSU, the baccalaureate examination with national coverage for admission to university, has minimum and maximum scores of 150 and 850, respectively. Each test, language and mathematics, considers 80 items each [26]. Results were expressed as mean \pm SD.

In both follow-up periods, the current nutritional status was assessed through the BMI which was also calculated using biological age derived from Tanner stages and expressed as Z-BMI [19-21]. 2013 SIMCE and 2017 PSU outcomes were considered dependent variables in each follow-up period.

\section{Statistical Analysis}

Comparisons between current nutritional status expressed as $2010 \mathrm{Z}$-BMI groups, N and overnutrition $(\mathrm{OW}+\mathrm{OB})$ were performed using chi-square or Fisher's exact tests for categorical variables and Student's $t$ test for comparisons of means. Variables were correlated using Pearson's and Spearman's correlation coefficients for continuous and categorical variables, respectively. A multivariate statistical modelling was performed using multiple linear regressions [27]. The model was defined in the statistical model based on 
Flores et al.: Overnutrition and Scholastic Achievement: Is There a Relationship? An 8-Year Follow-Up Study

Table 1. Demographic, socioeconomic, sociocultural, family and educational characteristics of the sample by gender and 2010 Z-BMI groups

\begin{tabular}{|c|c|c|c|c|c|c|}
\hline \multirow[t]{2}{*}{ Control variables } & \multicolumn{2}{|c|}{ Males $(n=263)$} & \multirow[t]{2}{*}{$\mathrm{P}$} & \multicolumn{2}{|c|}{ Females $(n=214)$} & \multirow[t]{2}{*}{$\mathrm{P}$} \\
\hline & $\begin{array}{l}N \\
(n=114)\end{array}$ & $\begin{array}{l}\text { overnutrition } \\
(O W+O B)(n=149)\end{array}$ & & $\begin{array}{l}N \\
(n=103)\end{array}$ & $\begin{array}{l}\text { overnutrition } \\
(O W+O B)(n=111)\end{array}$ & \\
\hline \multicolumn{7}{|l|}{ Demographic variables } \\
\hline Mean age $\pm S D$, years & $10.8 \pm 0.6$ & $10.7 \pm 0.4$ & $0.189^{a}$ & $10.7 \pm 0.6$ & $10.7 \pm 0.4$ & $0.510^{\mathrm{a}}$ \\
\hline \multicolumn{7}{|c|}{ Socioeconomic and sociocultural variables } \\
\hline \multicolumn{7}{|c|}{ Socioeconomic status, \% of cases } \\
\hline High & 15.8 & 10.1 & & 15.5 & 10.8 & \\
\hline Medium & 44.7 & 46.3 & $0.370^{\mathrm{b}}$ & 46.6 & 44.1 & $0.439^{b}$ \\
\hline Low & 39.5 & 43.6 & & 37.9 & 45.1 & \\
\hline \multicolumn{7}{|c|}{ Paternal schooling, years } \\
\hline$<12$ & 36.9 & 27.9 & $0.903^{b}$ & 32.6 & 34.7 & $0.761^{b}$ \\
\hline$\geq 12$ & 63.1 & 72.1 & & 67.4 & 65.3 & \\
\hline \multicolumn{7}{|c|}{ Maternal schooling, years } \\
\hline$<12$ & 34.4 & 33.6 & $0.141^{\mathrm{b}}$ & 42.9 & 33.9 & $0.188^{b}$ \\
\hline$\geq 12$ & 65.6 & 66.4 & & 57.1 & 66.1 & \\
\hline \multicolumn{7}{|c|}{ Family variables } \\
\hline \multicolumn{7}{|c|}{ Family recreation activities, $\%$ of cases } \\
\hline Always & 33.4 & 30.9 & & 36.9 & 41.5 & \\
\hline Frequently & 41.2 & 40.9 & $0.855^{\mathrm{b}}$ & 39.8 & 33.3 & $0.416^{\mathrm{b}}$ \\
\hline Sometimes, & 14.9 & 18.8 & & 9.7 & 15.3 & \\
\hline Never & 10.5 & 9.4 & & 13.6 & 9.9 & \\
\hline \multicolumn{7}{|c|}{ Family support for studies at home, $\%$ of cases } \\
\hline Always & 47.4 & 51.0 & & 46.6 & 51.4 & \\
\hline Sometimes & 45.6 & 44.3 & $0.668^{b}$ & 49.5 & 43.2 & $0.617^{b}$ \\
\hline Never & 7.0 & 4.7 & & 3.9 & 5.4 & \\
\hline
\end{tabular}

Table 1 continued on next page

statistical parameters [28]. In the linear regression analysis, the stepwise procedure was used to establish the most important variables that could affect LSA, MSA, and UNESA in the 2009 SIMCE tests (dependent variable). 2010 Z-BMI was considered as independent variable and nutritional quality of diet, scheduled exercise and socioeconomic, sociocultural, family and educational variables as control variables. A saturated model (independent variable + dependent variable) and an adjusted model including the control variables that correlated significantly with SA or relevant variables for an adequate fit of the model were considered. The level of statistical significance of the study was set at $\mathrm{p}<0.05$. Four and 8 years later, 2013 SIMCE and 2017 PSU outcomes were considered dependent variables and $2010 \mathrm{Z}$-BMI the independent variable. Data were analyzed using the Stata Statistical Software, version 14 (College Station, TX, USA).

\section{Results}

\section{Characteristics of the Sample}

According to the $2010 \mathrm{Z}-\mathrm{BMI}, 45.5 \%$ of school age children were $\mathrm{N}$ and $32.1 \%$ and $22.4 \%$ presented with OW and OB, respectively. $2010 \mathrm{Z}$-BMI was not significantly associated with gender; $43.4 \%$ and $33.4 \%$ of males presented with OW and OB, respectively, among females, the respective rates were $48.1 \%$ and $30.4 \%$ (Fisher's exact test $\mathrm{p}=0.310$ ). Table 1 shows that demographic, socioeconomic, sociocultural, family and educational characteristics of the sample did not differ significantly by gender and 2010 Z-BMI groups. 2010 Z-BMI values did 
Flores et al.: Overnutrition and Scholastic Achievement: Is There a Relationship? An 8-Year Follow-Up Study

Table 1. Continued

\begin{tabular}{|c|c|c|c|c|c|c|}
\hline \multirow[t]{2}{*}{ Control variables } & \multicolumn{2}{|c|}{ Males $(n=263)$} & \multirow[t]{2}{*}{$\mathrm{P}$} & \multicolumn{2}{|c|}{ Females $(n=214)$} & \multirow[t]{2}{*}{$\mathrm{P}$} \\
\hline & $\begin{array}{l}N \\
(n=114)\end{array}$ & $\begin{array}{l}\text { overnutrition } \\
(O W+O B)(n=149)\end{array}$ & & $\begin{array}{l}N \\
(n=103)\end{array}$ & $\begin{array}{l}\text { overnutrition } \\
(O W+O B)(n=111)\end{array}$ & \\
\hline \multicolumn{7}{|l|}{ Educational variables } \\
\hline \multicolumn{7}{|l|}{ Type of school, $\%$ of cases } \\
\hline Public & 29.8 & 32.9 & \multirow{3}{*}{$0.116^{b}$} & 35.0 & 32.4 & \multirow{3}{*}{$0.904^{b}$} \\
\hline Private subsidized & 59.7 & 63.1 & & 58.2 & 61.3 & \\
\hline Private non-subsidized & 10.5 & 4.0 & & 6.8 & 6.3 & \\
\hline \multicolumn{7}{|c|}{ Number of repeated years, $\%$ of cases } \\
\hline None & 86.8 & 92.0 & \multirow{4}{*}{$0.067^{c}$} & 94.2 & 89.2 & \multirow{4}{*}{$0.085^{c}$} \\
\hline 1 & 9.7 & 7.4 & & 5.8 & 9.9 & \\
\hline 2 & 3.5 & 0.0 & & 0.0 & 0.9 & \\
\hline 3 & 0.0 & 0.6 & & 0.0 & 0.0 & \\
\hline \multicolumn{7}{|c|}{ Student relationship with their teachers, \% of cases } \\
\hline Very adequate & 31.6 & 30.2 & \multirow{5}{*}{$0.780^{\mathrm{c}}$} & 37.9 & 40.5 & \multirow{5}{*}{$0.293^{c}$} \\
\hline Somewhat adequate & 48.2 & 44.3 & & 44.6 & 38.8 & \\
\hline Fair & 19.3 & 24.2 & & 14.6 & 20.7 & \\
\hline Something inappropriate & 0.9 & 1.3 & & 1.9 & 0.0 & \\
\hline Inadequate & 0.0 & 0.0 & & 1.0 & 0.0 & \\
\hline \multicolumn{7}{|c|}{ Student relationship with their classmates, $\%$ of cases } \\
\hline Very adequate & 41.2 & 38.9 & \multirow{5}{*}{$0.908^{c}$} & 40.8 & 37.9 & \multirow{5}{*}{$0.493^{c}$} \\
\hline Somewhat adequate & 36.9 & 35.6 & & 33.0 & 27.9 & \\
\hline Fair & 18.4 & 21.5 & & 24.2 & 28.8 & \\
\hline Something inappropriate & 0.9 & 2.0 & & 1.0 & 4.5 & \\
\hline Inadequate & 2.6 & 2.0 & & 1.0 & 0.9 & \\
\hline
\end{tabular}

not differ significantly through the follow-up study periods $(r=0.90 p=0.001)$; this is the reason why all comparisons in the follow-up study were made with the $2010 \mathrm{Z}$-BMI.

\section{Nutritional Quality of Diet by Gender and 2010 Z-BMI Groups}

The proportion of children with unhealthy diet was slightly but significantly higher in overnourished males compared with their normal-weight peers (fig. 1); however, in this group, also a high percentage of children with healthy diets was observed $(p=0.037)$. In females, a similar situation was observed $(p=0.050)$.

\section{Schedule Exercise by Gender and 2010 Z-BMI Groups}

No significant differences were observed between schedule exercise by gender and Z-BMI groups (fig. 2).

Correlations between 2009 SIMCE Outcomes and 2010 Z-BMI

Figure 3 shows scatterplots of 2009 SIMCE scores, for LSA, MSA and UNESA scores and 2010 Z-BMI by gender. Pearson's correlation coefficients were not significant both in males and females. 
Fig. 1. Nutritional quality of diet expressed as unhealthy (black column), fair (grey column) and healthy (white column) by gender and 2010 BMI Z-score groups (N, normal; 0 , overnutrition $=$ overweight + obesity). ${ }^{\text {a Chi-square }}$ test.

Fig. 2. Schedule exercise expressed as physically inactive (black column), moderately active (grey column) and physically active (white column) by gender and 2010 BMI Z-score groups (N, normal; 0 , overnutrition = overweight + obesity). ${ }^{\text {a Chi-square }}$ test.
Flores et al.: Overnutrition and Scholastic Achievement: Is There a Relationship? An 8-Year Follow-Up Study
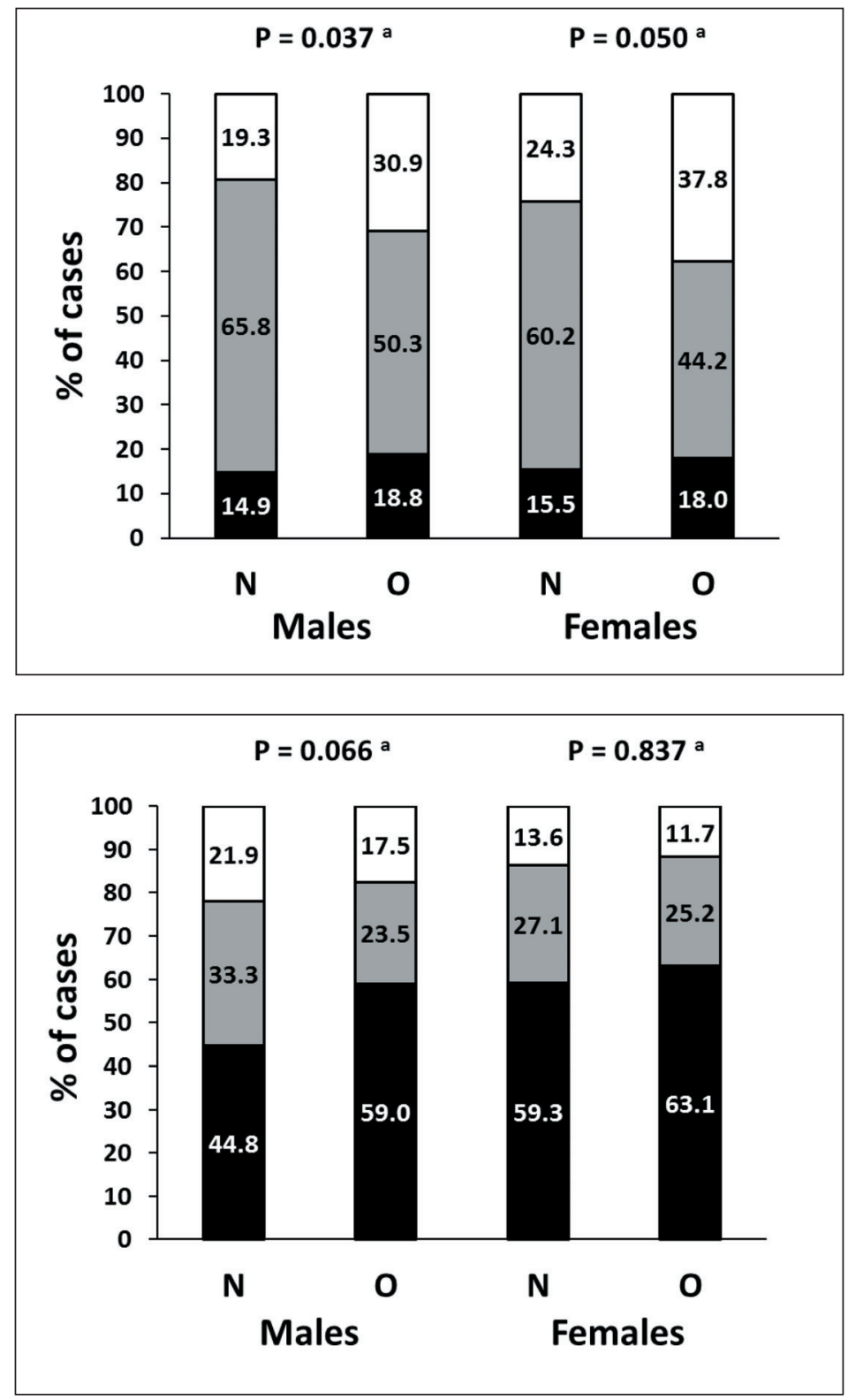

Correlations between 2009 SIMCE Outcomes and 2010 Z-BMI, Nutritional Quality of Diet,

Schedule Exercise, Socio-Economic, Socio-Cultural, Family as well as Educational

Variables and Gender

2009 SIMCE outcomes in the different tests were not significantly correlated with 2010 Z-BMI, nutritional quality of diet, schedule exercise, and student relationships with their teachers and with their classmates (table 2). Positive and significant correlations between 2009 SIMCE outcomes in LSA, MSA and UNESA were observed with socioeconomic status and parental schooling in both genders. However, a negative and significant correlation was observed with the number of repeated school years with the exception of LSA in females. In females, type of school (private non-subsidized schools) positively and significantly correlated with all tests. Males achieved significantly higher scores in MSA and UNESA and females in LSA, but these differences were not significant. 
Fig. 3. Dispersion diagram of language (LSA), mathematics (MSA) and understanding of natural environment scholastic achievement (UNESA) scores in the Education Quality Measurement System (2009 SIMCE) and current nutritional status expressed as 2010 BMI Z-score (2010 Z-BMI) by gender. LSA Pearson's correlation coefficient: $r=0.059, p>0.05$ (males) and $r=-0.109, \mathrm{p}>0.05$ (females); MSA Pearson's correlation coefficient: $r=0.069, p>0.05$ (males) and $r=-0.081, p>0.05$ (females); UNESA Pearson's correlation coefficient: $r=0.027, p>$ 0.05 (males) and $r=-0.053, \mathrm{p}>$ 0.05 (females).

Flores et al.: Overnutrition and Scholastic Achievement: Is There a Relationship? An 8-Year Follow-Up Study

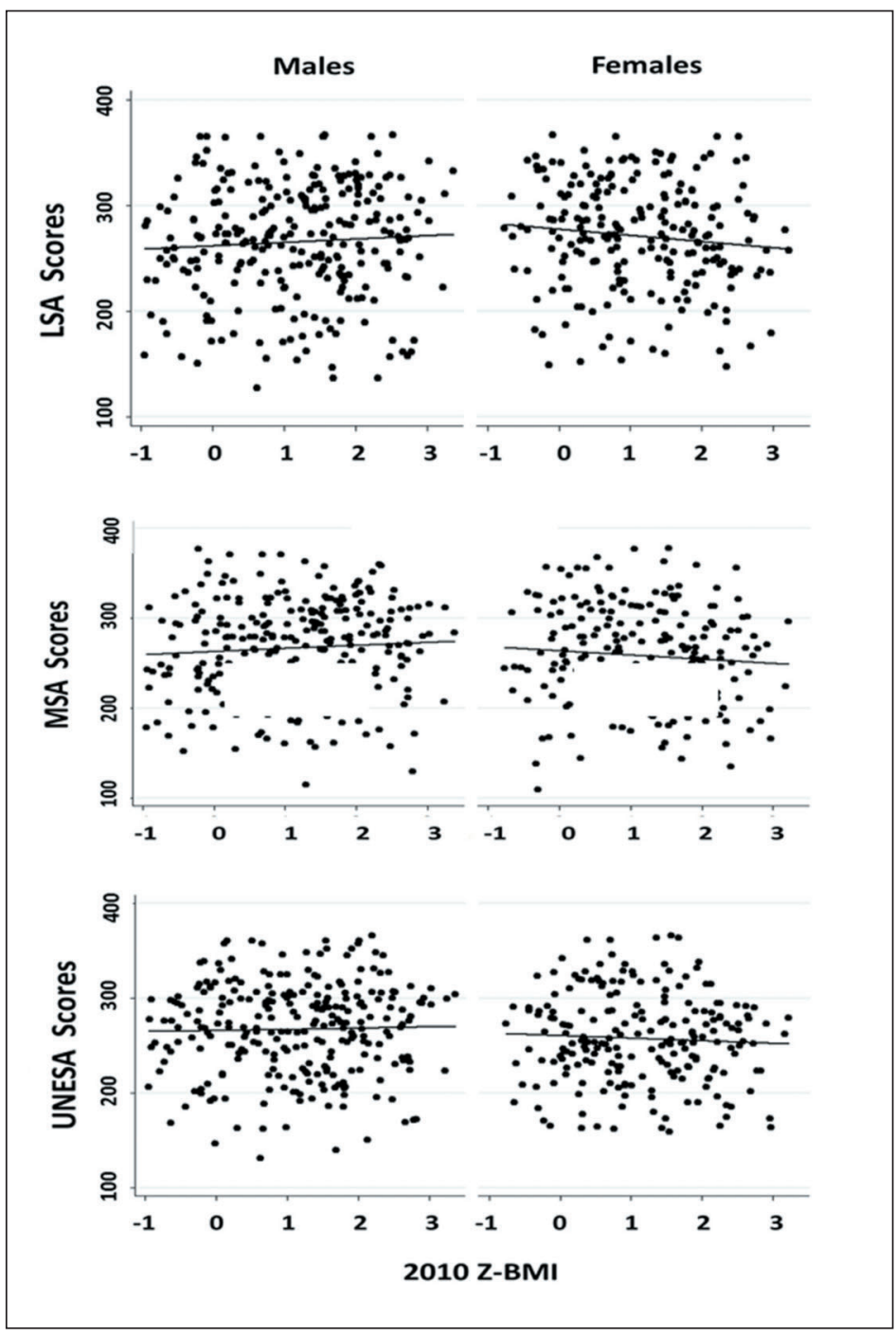

Multiple Regression Analysis between 2009 SIMCE Outcomes in LSA, MSA or UNESA,

(Dependent Variables) and 2010 Z-BMI (Independent Variables) and Most Relevant

Control Variables

Table 3 shows the multiple regression analysis between 2009 SIMCE outcomes in LSA, MSA or UNESA (dependent variables) andh 2010 Z-BMI (independent variables) and most relevant control variables. 2010 Z-BMI did not contribute to explain 2009 SIMCE outcomes in these tests, but variables such as socioeconomic status, the number of repeated school years, and maternal schooling contributed significantly to explain the LSA (Model $\mathrm{R}^{2}=0.178$; $\mathrm{p}<0.00001$ ), besides of gender in MSA (Model $\mathrm{R}^{2}=0.205 ; \mathrm{p}<0.00001$ ) and UNESA (Model $\mathrm{R}^{2}=0.272 ; \mathrm{p}<0.00001$ ) scores in the adjusted models..

\section{Associations between 2009 SIMCE, 2013 SIMCE or 2017 PSU Outcomes and 2010 Z-BMI}

Groups by Gender

No significant differences with regard to 2010 Z-BMI groups and gender were found between 2009 and 2013 SIMCE and 2017 PSU outcomes in the different tests (table 4). 84\% and $62 \%$ of the original sample took the 2013 SIMCE 4 years later and the 2017 PSU 8 years later, respectively. 
Flores et al.: Overnutrition and Scholastic Achievement: Is There a Relationship? An 8-Year Follow-Up Study

Table 2. Correlation coefficients between scholastic achievement (SA) in the Quality Education Measurement System (2009 SIMCE) tests of language (LSA), mathematics (MSA) and understanding of the natural environment (UNESA) and current nutritional status, nutritional quality of diet, physical activity, socioeconomic, sociocultural, family and educational variables by gender $(n=477)$

\begin{tabular}{|c|c|c|c|c|c|c|}
\hline \multirow[t]{2}{*}{ Variables } & \multicolumn{3}{|c|}{ Males (n=263) } & \multicolumn{3}{|c|}{ Females $(n=214)$} \\
\hline & LSA & MSA & UNESA & LSA & MSA & UNESA \\
\hline \multicolumn{7}{|c|}{ Current nutritional status, nutritional quality of diet and physical activity variables ${ }^{a}$} \\
\hline $2010 \mathrm{Z}-\mathrm{BMI}$ & 0.059 & 0.069 & 0.027 & -0.109 & -0.081 & -0.053 \\
\hline Nutritional quality of diet, score & 0.080 & 0.101 & 0.107 & 0.096 & 0.110 & 0.106 \\
\hline Schedule exercise, score & -0.018 & -0.008 & -0.057 & 0.077 & 0.059 & 0.099 \\
\hline \multicolumn{7}{|l|}{ Socioeconomic and sociocultural variables ${ }^{a}$} \\
\hline Socioeconomic status ${ }^{b}$ & $0.235^{* * * *}$ & $0.292^{* * * *}$ & $0.331^{* * * *}$ & $0.390^{* * * *}$ & $0.342^{* * * *}$ & $0.465^{* * * *}$ \\
\hline Paternal schooling, years & $0.228^{* * *}$ & $0.257^{* * * *}$ & $0.299 * * * *$ & $0.394^{* * * *}$ & $0.317^{* * * *}$ & $0.457^{* * * *}$ \\
\hline Maternal schooling, years & $0.228^{* * *}$ & $0.304^{* * * *}$ & $0.340^{* * * *}$ & $0.418^{* * * *}$ & $0.402^{* * * *}$ & $0.493^{* * * *}$ \\
\hline \multicolumn{7}{|l|}{ Family variables ${ }^{b}$} \\
\hline Family recreation activities & $0.138^{*}$ & 0.066 & 0.066 & $0.158^{*}$ & 0.063 & 0.057 \\
\hline Family support for studies at home & -0.090 & -0.110 & -0.033 & -0.064 & $-0.170^{*}$ & $-0.135^{*}$ \\
\hline \multicolumn{7}{|l|}{ Educational variables ${ }^{b}$} \\
\hline Number of repeated years, years ${ }^{a}$ & $-0.244^{* * * *}$ & $-0.268^{* * * *}$ & $-0.218^{* * *}$ & -0.114 & $-0.165^{*}$ & $-0.192^{* *}$ \\
\hline Student relationship with their teachers & 0.052 & 0.004 & 0.046 & 0.030 & 0.016 & 0.028 \\
\hline Student relationship with their classmates & 0.065 & 0.058 & -0.011 & 0.090 & 0.001 & 0.012 \\
\hline Type of school (non-subsidized schools) & 0.084 & 0.113 & 0.101 & $0.194^{* *}$ & $0.148^{*}$ & $0.160^{*}$ \\
\hline 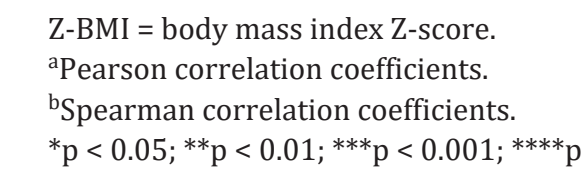 & 0.0001 & & & & & \\
\hline
\end{tabular}

\section{Discussion}

The findings of this study reveal that in male and female school age children of the 5 th elementary school grade 2010-Z-BMI and 2009 SIMCE outcomes were not significantly associated. As a consequence, there were no significant differences in LSA, MSA and UNESA scores between school age children with overnutrition compared with their $\mathrm{N}$ peers. Variables such as socioeconomic status, the number of repeated school years, maternal schooling, and gender were significantly associated with 2009 SIMCE scores and are strong predictors of SA.

These results are not in agreement with other studies and systematic reviews which reported a negative and significant association between overnutrition of children or teenagers and SA [29-35]. It is unclear why overnutrition did not show a significant correlation with SIMCE 2009 outcomes in our study where most part of the sample presented with overnutrition (56.7\% and $51.8 \%$ of men and women, respectively). The findings from other authors revealed that obese children had the highest prevalence of school absences and repetition rates and, thus, low school engagement [36]; however, this is not the case for the sample of the present study.

Our previous findings of studies carried out in Chile and those from other countries did not find any associations between the current nutritional status (according to Z-BMI) and SA; these results confirmed that Z-BMI is not suitable to explain SA [37-46]. 
Flores et al.: Overnutrition and Scholastic Achievement: Is There a Relationship? An 8-Year Follow-Up Study

Table 3. Multiple regression analysis between scholastic achievement (SA) in the Quality Education Measurement System (2009 SIMCE) tests of language (LSA), mathematics (MSA) and understanding of the natural environment (UNESA) and 2010 body mass index Z-score (2010 Z-BMI) (independent variable) and most relevant control variables

\begin{tabular}{|c|c|c|c|c|}
\hline Variables & Coefficient & Standard deviation & $\begin{array}{l}\mathrm{T} \text { for } \mathrm{H} 0: \\
\text { Parameter }=0\end{array}$ & $\mathrm{p}>|\mathrm{t}|$ \\
\hline \multicolumn{5}{|l|}{$L S A$} \\
\hline Constant & 204.2027 & 13.6882 & 14.92 & 0.000 \\
\hline 2010 Z-BMI & -1.0512 & 2.4353 & -0.43 & 0.666 \\
\hline $\begin{array}{l}\text { Gender } \\
\text { Ref }=\text { males }\end{array}$ & 5.8384 & 4.8804 & 1.20 & 0.232 \\
\hline $\begin{array}{l}\text { Medium socioeconomic status } \\
\text { Ref = low socioeconomic status }\end{array}$ & 14.9370 & 6.2840 & 2.38 & 0.018 \\
\hline $\begin{array}{l}\text { High socioeconomic status } \\
\text { Ref = low Socioeconomic status }\end{array}$ & 25.7364 & 11.6154 & 2.22 & 0.027 \\
\hline $\begin{array}{l}\text { Type of school = private subsidized } \\
\text { Ref }=\text { public }\end{array}$ & 9.1591 & 5.3653 & 1.71 & 0.089 \\
\hline $\begin{array}{l}\text { Type of school = private non-subsidized } \\
\text { Ref }=\text { public }\end{array}$ & -18.1867 & 12.3813 & -1.47 & 0.143 \\
\hline Number of repeated school years & -22.5798 & 6.81285 & -3.31 & 0.001 \\
\hline Maternal schooling, years & 2.3589 & 0.97106 & 2.43 & 0.016 \\
\hline Paternal schooling, years & 2.0182 & 1.0295 & 1.96 & 0.051 \\
\hline \multicolumn{5}{|c|}{ Model $\mathrm{R}^{2}=0.178 ;$ Root MSE $=48.886 ;$ Model F value $(9.400)=9.63 ; \mathrm{p}<0.00001(\mathrm{n}=477)$} \\
\hline \multicolumn{5}{|l|}{$M S A$} \\
\hline Constant & 212.7649 & 13.54869 & 15.70 & 0.000 \\
\hline 2010 Z-BMI & -0.4310 & 2.4104 & -0.18 & 0.858 \\
\hline $\begin{array}{l}\text { Gender } \\
\text { Ref }=\text { males }\end{array}$ & -10.8198 & 4.8307 & -2.24 & 0.026 \\
\hline $\begin{array}{l}\text { Medium socioeconomic status } \\
\text { Ref = low socioeconomic status }\end{array}$ & 14.5071 & 6.2200 & 2.33 & 0.020 \\
\hline $\begin{array}{l}\text { High socioeconomic status } \\
\text { Ref = low socioeconomic status }\end{array}$ & 34.5246 & 11.4970 & 3.00 & 0.003 \\
\hline $\begin{array}{l}\text { Type of school = private subsidized } \\
\text { Ref: public }\end{array}$ & 7.4882 & 5.3106 & 1.41 & 0.159 \\
\hline $\begin{array}{l}\text { Type of school = private non-subsidized } \\
\text { Ref: public }\end{array}$ & -13.2312 & 12.25501 & -1.08 & 0.281 \\
\hline Number of repeated school years & -27.4441 & 6.7434 & -4.07 & 0.000 \\
\hline Maternal schooling, years & 3.1344 & 0.9612 & 3.26 & 0.001 \\
\hline Paternal schooling, years & 0.7053 & 1.0190 & 0.69 & 0.489 \\
\hline
\end{tabular}

Model $\mathrm{R}^{2}=0.205 ;$ Root MSE = 48.388; Model F value $(9.400)=11.43 ; \mathrm{p}<0.00001(\mathrm{n}=477)$

In the present study, nutritional quality of diet did not contribute to explain 2009 SIMCE outcomes; this is in agreement with other findings [47]. Other studies did not find any conclusive association between the impact of dietary intake and SA [48, 49]. Schedule exercise did not have any effect on 2009 SIMCE outcomes. These findings are in agreement with our previous findings and with those from other authors; however, results are controversial since some authors have found a positive and significant association between the level of physical activity and SA but others did not [47, 50-51].

SA is more properly explained by child intelligence, parental intelligence, schooling level (especially maternal schooling). the occurrence of undernutrition in the first year of life, 
Flores et al.: Overnutrition and Scholastic Achievement: Is There a Relationship? An 8-Year Follow-Up Study

Table 3. Continued

\begin{tabular}{|c|c|c|c|c|}
\hline Variables & Coefficient & Standard deviation & $\begin{array}{l}\mathrm{T} \text { for } \mathrm{H} 0: \\
\text { Parameter }=0\end{array}$ & $\mathrm{p}>|\mathrm{t}|$ \\
\hline \multicolumn{5}{|l|}{ UNESA } \\
\hline Constant & 202.3869 & 11.5510 & 17.52 & 0.000 \\
\hline 2010 Z-BMI & 0.0783 & 2.0550 & 0.04 & 0.970 \\
\hline $\begin{array}{l}\text { Gender } \\
\text { Ref }=\text { males }\end{array}$ & -10.7386 & 4.1184 & -2.61 & 0.009 \\
\hline $\begin{array}{l}\text { Medium socio-economic status } \\
\text { Ref = low socio-economic status }\end{array}$ & 15.1317 & 5.3029 & 2.85 & 0.005 \\
\hline $\begin{array}{l}\text { High socio-economic status } \\
\text { Ref = low socio-economic status }\end{array}$ & 34.5302 & 9.8019 & 3.52 & 0.000 \\
\hline $\begin{array}{l}\text { Type of school = private subsidized } \\
\text { Ref = public }\end{array}$ & 3.7274 & 4.5276 & 0.82 & 0.411 \\
\hline $\begin{array}{l}\text { Type of school = private non-subsidized } \\
\text { Ref }=\text { public }\end{array}$ & -16.5958 & 10.4481 & -1.59 & 0.113 \\
\hline Number of repeated school years & -22.4633 & 5.7491 & -3.91 & 0.000 \\
\hline Maternal schooling, years & 3.1286 & 0.8194 & 3.82 & 0.000 \\
\hline Paternal schooling, years & 1.5364 & 0.8687 & 1.77 & 0.078 \\
\hline
\end{tabular}

nutritional background parameters, head circumference (the anthropometric indicator of both nutritional background and brain development), brain volume, and some demographic and educational system variables [37-41].

In the present study, the regression models showed that variables such as gender, socioeconomic status, the number of repeated school years, and maternal schooling are stronger risk factors for 2009 SIMCE outcomes in LSA, MSA and UNESA, although with a low explanatory power in the variance. Males significantly outperformed females in MSA and UNESA while females outperformed males in LSA, although differences were not significant. These findings are consistent with those from other investigators who explored the effect of sex differences in data obtained during one decade by the PISA assessments including the mathematics and reading performances of nearly 1.5 million 15 -year-olds in 75 countries. Across nations, males scored higher than females in mathematics, but lower than females in reading [52]. Similarly, the regression models showed a positive effect on 2009 SIMCE outcomes when socioeconomic status and maternal schooling increased and a negative effect when the number of repeated school years increased. This is in agreement with the findings from several studies whose authors concluded that SA does not depend solely on the current nutritional status of school age children; the possible significant association between Z-BMI and SA were not significant after including socioeconomic strata and maternal education variables in the statistical regression model $[8,9,53]$. These variables could be stronger predictors of SA, indicating that overnutrition was a marker but not a causal factor for SA; This is also consistent with findings from other authors who found that school age children with OW showed lower SA compared with their N peers; however, these associations were not significant after adjusting for variables such as parental schooling, sociodemographic factors, breakfast consumption, and screen time [42, 43].

The importance of maternal schooling as a significant predictor of 2009 SIMCE outcomes in LSA, MSA, and UNESA was also evident in the current study and is in agreement with other findings $[37,39-41,54]$. Other authors found that maternal schooling could have a consid- 
Flores et al.: Overnutrition and Scholastic Achievement: Is There a Relationship? An 8-Year Follow-Up Study

Table 4. Scholastic achievement of school age children in the Quality Education Measurement System (2009 SIMCE) tests at the end of the first cycle of elementary school (4th grade of elementary school), in the 2013 SIMCE tests when they graduated from elementary school (8th grade of elementary school) and in the 2017 University Selection Test (2017 PSU) for university admission when they graduated from high school (4th grade of high school) by area of measurement, gender and 2010 Z-BMI groups ${ }^{\text {a }}$

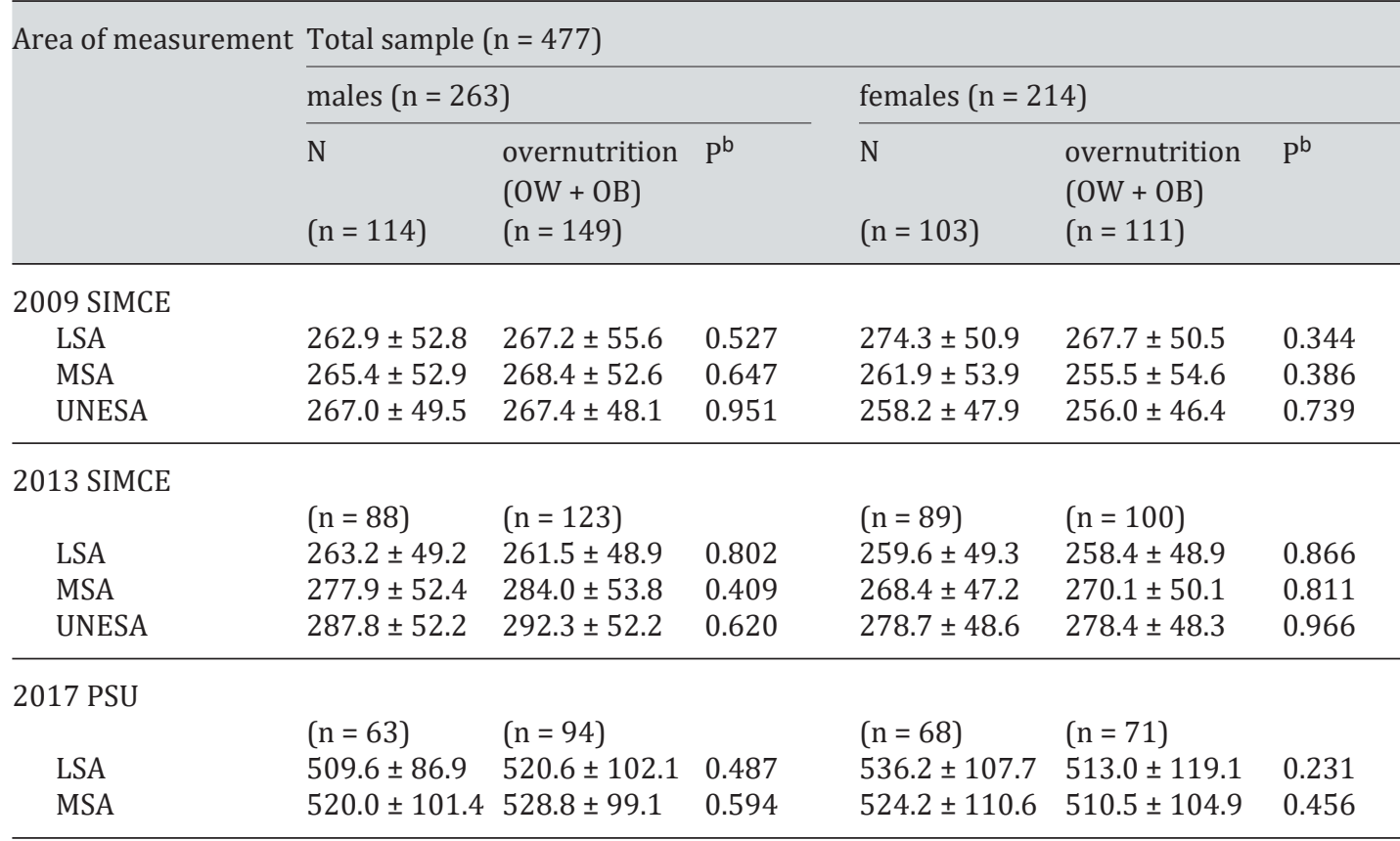

Z-BMI = Body mass index Z-score; $\mathrm{N}$ = normal weight; $\mathrm{OW}=$ overweight; $\mathrm{OB}$ = obesity; LSA = language scholastic achievement; MSA = mathematics scholastic achievement; UNESA = understanding of the natural environment scholastic achievement.

${ }^{\text {a }}$ cores are expressed as mean \pm SD.

bStudent's t test for independent samples with equality of variances at the 0.05 level of probability.

Pearson correlation coefficient between 2010 Z-BMI and 2013 SIMCE outcomes: $\operatorname{LSA}(\mathrm{r}=0.023, \mathrm{p}>0.05$ (males) and $r=-0.108, p>0.05$ (females)); MSA $(r=0.080, p>0.05$ (males) and $r=-0.030, p>0.05$ (females)); UNESA ( $r=0.096, p>0.05$ (males) and $r=-0.085, p>0.05$ (females)).

Pearson correlation coefficient between 2010 Z-BMI and 2017 PSU outcomes: LSA $(r=0.088, p>0.05$ (males) and $\mathrm{r}=-0.136, \mathrm{p}>0.05$ (females)); MSA ( $\mathrm{r}=0.012, \mathrm{p}>0.05$ (males) and $\mathrm{r}=-0.111, \mathrm{p}>0.05$ (females)).

erable effect on a child's intelligence, because mothers are the main source of intellectual stimulation and of the enrichment of the psychosocial environment, which also affects SA as this parameter and intelligence are closely related [37, 39, 40, 41, 55].

Socioeconomic status was positively and significantly correlated with 2009 SIMCE outcomes in LSA, MSA and UNESA, and was also a significant predictor of SA. School age children with low socioeconomic status obtained the lowest SA scores since they have lowered intelligence levels compared with their peers with or high socioeconomic status [37, 39-41]. Poverty brings negative consequences for child development and family structure, including the school environment, nutritional status, cognition, SA, dropout rates, and job status [37, $39-41,56]$.

Higher repetition rates could adversely affect SA, as observed in our study where a significant negative correlation was observed between the number of repeated school years and 2009 SIMCE outcomes in LSA, MSA and UNESA. Other authors found that students who 
Flores et al.: Overnutrition and Scholastic Achievement: Is There a Relationship? An 8-Year Follow-Up Study

became OB during the study period had significantly higher repetition rates compared with their N peers [14]; however, this was not observed in the present study

Type of school did not contribute to explain 2009 SIMCE outcomes in the present study. However, other findings confirmed that students attending private non-subsidized schools achieved significantly higher SA scores compared with students enrolled in public and private subsidized schools $[37,41,54]$. Private non-subsidized schools probably create a more stimulating environment and provide a more adequate infrastructure which favors the learning process, while parents themselves have higher levels of education and income. Students attending these schools develop higher levels of intellectual abilities, have higher head circumference-for-age Z-scores, and are probably trained by teachers with better academic backgrounds who apply more efficient teaching methodologies [37, 41, 54]. This should be deeply analyzed, since it might be a barrier and an inequality factor for SA, educational situation along the school year, and later job status [56].

Overnourished children did not achieve significantly lower 2013 SIMCE and 2017 PSU outcomes after 4 and 8 years of follow-up study, respectively. In summary, our data reveal that there are no associations between 2010 Z-BMI and SA during an 8-year follow-up study. As a consequence, these findings do not confirm the hypothesis formulated for this study that overnourished schoo age children achieve significantly lower SA compared with their $\mathrm{N}$ peers. A limitation of the present study is that these results should be considered as showing a statistical association and do not represent a direct cause and effect relationship, by which further research is needed. Notwithstanding, this study highlights the relevance of these individual and standardized tests with countrywide coverage in Chile as a measuring tool of the quality of education. These findings may be useful for planning public policies in the health and educational sectors in this and other countries.

\section{Acknowledgments}

The authors are grateful to the Agency for Quality Education, the Studies Center of the Ministry of Education of Chile, and to the Department of Evaluation, Measurement and Educational Registry (DEMRE) of the University of Chile for all the facilities given to carry out this research, for reviewing, approving and authorizing this study, and for providing the 2009 SIMCE results. We would like to thank the principals and teachers of the educational establishments and parents and their children, which made possible the realization of this study. We are also grateful to Dr. Oscar Brunser, MD, for helpful comments and suggestions. The data for the present article are part of a thesis submitted by the first author O. Flores, R.D., MSc, in partial fulfilment of the requirements for a Master of Sciences in Nutrition and Food degree from the Dr. Fernando Monckeberg Barros, Institute of Nutrition and Food Technology (INTA), University of Chile. Date were presented in part at the 4th Congress of the European Academy of Paediatric Societies (EAPS), Istanbul, Turkey, October 5-9, 2012.

\section{Authors' Contributions}

DIM is guarantor, and participated in all the steps of the research. DIM and OCF conceived and designed the study. OCF, YZO, and BDL analyzed the data. OCF and DIM wrote the first draft of the manuscript. All authors reviewed the manuscript critically and approved the final version of the manuscript.

\section{Ethics Approval}

All procedures performed in studies involving human participants were in accordance with the ethical standards of the Committee of Bioethics of the National Fund for Scientific and Technologic Development (FONDECYT) (reference No. 18/FONDECYT/EDUCATION/544 dated on Jun 3 2010), Committee of Ethics in 
Studies on Humans of the Dr. Fernando Monckeberg Barros, Institute of Nutrition and Food Technology (INTA), University of Chile (reference No. 8907-0/2011-EKU, 285/PI/11) and with the 1964 Helsinki declaration and its later amendments or comparable ethical standards [16]. Informed consent was obtained from all individual participants included in the study.

\section{Funding}

This work was supported by Grants 1100431 and 1150524 from the National Fund for Scientific and Technologic Development (FONDECYT) (PI: Daniza M. Ivanovic).

\section{Disclosure Statement}

The authors note no conflicts of interest.

\section{References}

1 Li P, Brown AW, Oakes JM, Allison DB: Comment on 'School-Based Obesity Prevention Intervention in Chilean Children: Effective in Controlling, but not Reducing Obesity'. J Obes 2015;2015:183528.

-2 Vio F, Albala C, Kain J: Nutrition transition in Chile revisited: mid-term evaluation of obesity goals for the period 2000-2010. Public Health Nutr 2008;11:405-412.

3 Chile. Ministerio de Salud (ed): Encuesta Nacional de Salud ENS Chile 2009-2010. Santiago, MINSAL, 2010.

-4 Friedlander SL, Larkin EK, Rosen CL, Palermo TM, Redline S: Decreased quality of life associated with obesity in school-aged children. Arch Pediatr Adolesc Med 2003;157:1206-1211.

-5 Atalupa S, Pulkki-Raback L, Hintsanen M, Ravaja N, Raitakari O, Telama R, Viikari JS, Keltikangas-Järvinen L: School performance as a predictor of adulthood obesity: a 21-year follow-up study. Eur J Epidemiol 2010;25: 267-274.

-6 Sigfúsdóttir ID, Kristjánsson AL, Allegrante JP: Health behaviour and academic achievement in Icelandic school children. Health Educ Res 2007;22:70-80.

7 Puhl RM, Latner JD: Stigma, obesity and the health of the nation's children. Psychol Bull 2007;133:557-580.

18 Datar A, Sturm R: Childhood overweight and parent- and teacher-reported behavior problems: evidence from a prospective study of kindergartners. Arch Pediatr Adolesc Med 2004;158:804-810.

$\checkmark 9$ Datar A, Sturm R, Magnabosco JL: Childhood obesity and academic achievement: evidence from a population based sample of kindergartners and first graders. Obesity Res 2004;12:58-68.

$\$ 10$ Datar A, Sturm R: Physical education in elementary school and body mass index: evidence from the early childhood longitudinal study. Am J Public Health 2004;94:1501-1506.

11 Ivanovic D: Relationships between obesity and nutrient intake in Chilean adolescents. Nutr Rep Int1988; 37:(2), 227-239.

12 Breslau N, Paneth NS, Lucia VC: The lingering academic deficits of low birth weight children. Pediatrics 2004; 114:1035-1040.

13 Robinson TN: Reducing children's television viewing to prevent obesity: a randomized controlled trial. JAMA 1999;282:1561-1567.

14 Datar A, Sturm R: Childhood overweight and elementary school outcomes. Int J Obes 2006;30:1449-1460.

15 Lin BH, Huang CL, French SA: Factors associated with women's and children's body mass indices by income status. Int J Obes Relat Metab Disord 2004;28:536-542.

-16 The World Medical Association: Human experimentation. Code of Ethics of the World Medical Association (Declaration of Helsinki). Br Med J 1964;2:177.

17 Chile's Government: SIMCE 2009 National results. Santiago, Curriculum and Evaluation Unit (UCE), Ministry of Education, 2010.

18 Gibson, R (ed): Principles of Nutritional Assessment. Oxford, Oxford University Press, 1990.

19 Tanner JM: Physical growth and development; in Forfar JO, Arneil GC (eds): Texbook of Pediatrics. Edinburgh, Churchill Livingstone, 1984, pp 278-330.

-20 De Onis M, Onyango AW, Borghi E, Siyam, A, Nishida C, Siekmann J: Elaboración de valores de referencia de la Organización Mundial de la Salud (OMS) para el crecimiento de escolares y adolescentes. Bull World Health Organ 2007;85:660-667.

21 Centers for Disease Control and Prevention, National Center for Health Statistics. CDC growth charts. www. cdc.gov/growthcharts/ (last accessed September 27, 2018).

-22 Burrows AR, Díaz BE, Sciaraffia MV, Gattas ZV, Montoya CA, Lera ML: Hábitos de ingesta y actividad física en escolares, según tipo de establecimiento al que asisten. Rev Med Chil 2008;136:53-63. 
Flores et al.: Overnutrition and Scholastic Achievement: Is There a Relationship? An 8-Year Follow-Up Study

-23 Godard C, Rodríguez M, Díaz N, Lera L, Salazar G, Burrows R: Valor de un test clínico para evaluar actividad física en niños. Rev Med Chil 2008;136:1155-1162.

24 Organización Mundial de la Salud: Recomendaciones mundiales sobre la actividad física para la salud. 2010, pp 17-20. www.who.int/rpc/guidelines/9789241599979/es/index.html (last accessed September 27, 2018).

-25 Álvarez ML, Muzzo S, Ivanovic D: Escala para medición del nivel socioeconómico en el área de la salud. Rev Med Chil 1985;113:243-249.

26 University of Chile. Statistical compendium year 2018 PSU: academic admission process. Santiago, University of Chile, Vice-rectory of Academic Affairs, Department of Evaluation, Measurement and Educational Registry (DEMRE). 2018.

27 Guilford J, Fruchter B (eds): Estadística Aplicada a la Psicología y a la Educación. México City, McGraw Hill, 1984.

-28 Victora CG, Huttly SR, Fuchs SC, Olinto MT. The role of conceptual frameworks in epidemiological analysis: a hierarchical approach. Int J Epidemiol. 1997;26:224-227.

29 Mo-suwan L, Lebel L, Puetpaiboon A, Junjana C: School performance and weight status of children and young adolescents in a transitional society in Thailand. Int J Obes 1999;23:272-277.

-30 Taras H, Potts-Datema W: Obesity and student performance at school. J Sch Health 2005;75:291-295.

-31 Kamijo K, Khan NA, Pontifex MB, Scudder MR, Drollette ES, Raine LB, Evans EM, Castelli DM, Hillman CH: The relation of adiposity to cognitive control and scholastic achievement in preadolescent children. Obesity (Silver Spring) 2012;20:2406-2411.

-32 Booth JN, Tomporowski PD, Boyle JM, Ness AR, Joinson C, Leary SD, Reilly JJ: Obesity_impairs academic attainment in adolescence: findings from ALSPAC, a UK cohort. Int J Obes 2014;38:1335-1342.

-33 Carey FR, Singh GK, Brown HS 3rd, Wilkinson AV: Educational outcomes associated with childhood obesity in the United States: cross-sectional results from the 2011-2012 National Survey of Children's Health. Int J Behav Nutr Phys Act 2015;12(suppl 1):S3.

-34 Morita N, Nakajima T, Okita K, Ishihara T, Sagawa M, Yamatsu K: Relationships among fitness, obesity, screen time and academic achievement in Japanese adolescents. Physiol Behav 2016;163:161-166.

-35 Burkhalter TM, Hillman CH: A narrative review of physical activity, nutrition, and obesity to cognition and scholastic performance across the human lifespan. Adv Nutr 2011;2:201S-206S.

-36 Halfon N, Larson K, Slusser W: Associations between obesity and comorbid mental health, developmental, and physical health conditions in a nationally representative sample of US children aged 10 to 17. Acad Pediatr 2013;13:6-13.

-37 Ivanovic DM, Pérez HT, Olivares MG, Díaz NS, Leyton BD, Ivanovic, RM: Scholastic achievement: a multivariate analysis of nutritional, intellectual, socioeconomic, sociocultural, familial, and demographic variables in Chilean school-age children. Nutrition 2004;20:878-889.

38 Ivanovic D, Pérez H, Leiva B, Almagià A, Díaz N, Leyton B, Urrutia MS, Larraín C, Olave P, Inzunza N, Ivanovic R: Neuropsychological parameters affecting the Academic Aptitude Test (AAT) achievement at the end of high school in 1996 and their impact on job status in 2002:A multifactorial approach in a follow-up study; in Madsen LE (ed): Achievement Tests: Types, Interpretations and Uses. New York, Nova Science Publishers, 2011, pp 139-190.

-39 Ivanovic D, Leiva B, Pérez H, Almagia A, Toro T, Urrutia MS, Inzunza N, Bosch E: Nutritional status, brain development and scholastic achievement of Chilean high school graduates from high and low intellectual quotient and socio-economic status. Br J Nutr 2002;87:81-92.

40 Ivanovic D, Leiva B, Pérez H, Inzunza N, Almagià A, Toro T, Urrutia MS, Cervilla J, Bosch E: Long-term effects of severe undernutrition during the first year of life on brain development and learning in Chilean high school graduates. Nutrition 2000;16:1056-1063.

-41 Ivanovic D, Valenzuela R, Almagià A, Barrera C, Arancibia V, Larraín C, Silva C, Billeke P, Zamorano F, Villagrán F, Orellana Y, Martínez V: Impact of anthropometric nutritional parameters on the University Selection Test in Chile: a multifactorial approach. Nutrition 2019;57:74-83.

-42 Abdelalim A, Ajaj N, Al-Tmimy A, Alyousefi M, Al-Rashaidan S, Hammoud MS, Al-Taiar A: Childhood obesity and academic achievement among male students in public primary schools in Kuwait. Med Princ Pract 2012; 21:14-19.

43 Veldwijk J, Fries MC, Bemelmans W, Haveman-Nies A, Smit HA, Koppelman GH, Wijga AH: Overweight and school performance among primary school children: the PIAMA Birth Cohort Study. Obesity (Silver Spring) 2012;20:590-596.

44 Barrigas C, Fragoso I: Obesity, academic performance and reasoning ability in Portuguese students between 6 and 12 years old. J Biosoc Sci 2012;44:165-179.

45 Alswat KA, Al-Shehri AD, Aljuaid TA, Alzaidi BA, Alasmari HD: The association between body mass index and academic performance. Saudi Med J 2017;38:186-191.

46 Baxter SD, Guinn CH, Tebbs JM, Royer JA: There is no relationship between academic achievement and body mass index among fourth-grade, predominantly African-American children. J Acad Nutr Diet 2013;113:551557.

47 Ibaceta C: Nutritional Status and scholastic achievement in the Education Quality Measurement System (SIMCE). MSc Thesis. Santiago, University of Chile, INTA, 2013. 
Flores et al.: Overnutrition and Scholastic Achievement: Is There a Relationship? An 8-Year Follow-Up Study

-48 Mhurchu CN, Gorton D, Turley M, Jiang Y, Michie J, Maddison R, Hattie J: Effects of free school breakfast programme on children's attendance, academic achievement and short-term hunger: results from a steppedwedge, cluster randomized controlled trial. J Epidemiol Community Health 2013;67:257-264.

-49 Jomaa LH, McDonnell E, Probart C: School feeding programs in developing countries: impacts on children's health and educational outcomes. Nutr Rev 2011;69:83-98.

50 Singh A, Uijtdewilligen L, Twisk JW, van Mechelen W, Chinapaw MJ: Physical activity and performance at school: a systematic review of the literature including a methodological quality assessment. Arch Pediatr Adolesc Med 2012;166:49-55.

51 Hattie J, Clinton J: Physical activity is not related to performance at school. Arch Pediatr Adolesc Med 2012; 166:678-679.

52 Stoet G, Geary DC: Sex differences in mathematics and reading achievement are inversely related: within- and across-nation assessment of 10 years of PISA data. PLoS One 2013;8:e57988.

-53 Judge S, Jahns L: Association of overweight with academic performance and social and behavioral problems: an update from the early childhood longitudinal study. J Sch Health 2007;77:672-678.

54 Ivanovic R, Castro C, Ivanovic D: No existe una teoría sobre el rendimiento escolar. Revista de Educación (Ministerio de Educación Pública de Chile) 1995;224:40-45.

-55 Voss W, Jungmann T, Wachtendorf M, Neubauer AP: Long-term cognitive outcomes of extremely low-birthweight infants: the influence of the maternal educational background. Acta Paediatr 2012;101:569-573.

-56 Ivanovic D, Rodríguez MP, Pérez H, Alvear J, Díaz N, Leyton B, Almagià AF, Toro TD, Urrutia MSC, Ivanovic RM: Twelve-year follow-up study of the impact of nutritional status at the onset of elementary school on later educational situation of Chilean school-age children. Eur J Clin Nutr 2008;62:18-31. 